\title{
Crowdfunding Under Market Feedback, Asymmetric Information And Overconfident Entrepreneur*
}

\author{
Anton Miglo ${ }^{\dagger}$
}

2018

\begin{abstract}
This article is the first one that considers a model of the choice between the different types of crowdfunding, which contains elements of the asymmetric information approach and behavioral finance (overconfident entrepreneurs). The model provides several implications, most of which have not yet been tested. Our model predicts that equity-based crowdfunding is more profitable than reward-based crowdfunding when an entrepreneur is overconfident. This is because either the entrepreneur learns from the sale of shares before making production decisions or because the crowd anticipates the entrepreneur's behavior when valuing the shares offered for sale. The model also predicts that an equilibrium can exist where high-quality firms use equity-based crowdfunding in equilibrium which contrasts the spirit of traditional results (for example pecking-order theory) where equity represents an inferior security. The latter has rational managers. It also contrasts traditional behavioral finance literature (for example, Fairchild (2005)) where equity is not issued in equilibrium.

Keywords: entrepreneurial finance, crowdfunding, asymmetric information, overconfidence, equity-based crowdfunding, reward-based crowdfunding, entrepreneurship and learning
\end{abstract}

JEL Codes: D82, G32, L11, L26, M13

\section{Introduction}

Modern crowdfunding ${ }^{1}$ is a method of raising funds from a large number of investors (crowd) usually done online. The amount of funds raised using crowd-

\footnotetext{
${ }^{*}$ We are grateful to Vincent Crawford, Gary Dushnitsky, Todd Kaplan, Peter Klein, Claire Leitch, Simon C Parker, Deborah Trask, Jason Pavunkovic, Kory Lippert, Alia Raza, Shane Smith, Michael Kidd, Jamie Grasman, Jonathon Dean, Melissa Toner, Erin Clark, the seminar participants at Coventry University London, two anonymous referees and all the participants of the numerous discussions on crowdfunding organized by www.journalofcapitalstructure.com website for their comments.

${ }^{\dagger}$ Birmingham City University, anton.miglo@bcu.ac.uk.

${ }^{1}$ Some researchers argue that in a broad sense crowdfunding existed even in the 19th century. See, for example: https://www.thenational.ae/arts-culture/how-writers-are-turning-
} 
funding has been steadily growing for the last 20 years. It was first used to finance a reunion tour for the British rock band, Marillion, in 1997 and is now used as a comprehensive validation tool for startups, corporates, and nonprofits. $^{2}$ In 2016, the amount of funds raised through crowdfunding passed that of venture capital funding for the first time, and, by 2025, the World Bank Report estimates that global investment through crowdfunding will reach $\$ 93$ billion. ${ }^{3}$ Crowdfunding is also a quickly growing area of research. ${ }^{4}$

This article makes two contributions to existing literature. It is the first paper that analyzes the choice between the different types of crowdfunding using a behavioral finance approach by studying the role of entrepreneurial overconfidence. There is a relatively small number of theoretical paper on crowdfunding, and they usually assume rational entrepreneurs. We know, however, that part of being a good entrepreneur is being very confident and optimistic about your idea $^{5}$ which borders with what is called overconfidence in behavioral economics and finance literature. In this paper we analyze the role of entrepreneurial overconfidence on crowdfunding decisions. It also contributes to the litearture that analyzes the role of asymmetrc information in crowdfunding decisions. Empirical literature usually recognizes the importance of asymmetric information in crowdfunding (see, among others, Mollick (2014) and Ahlers, Cumming, Guenther, and Schweizer (2015)). These findings encouraged theoretical reserach in this area. Miglo and Miglo (2018) argue that under asymmetric information between entrepreneurs and potential investors (funders) about firms' projects, high-quality firms are not able to signal their quality by choosing a particular crowdfunding method when a one-period setting is considered (one-campaign setting). Low-quality firms will always mimick high-quality firms (similar to the traditional market for lemons idea (Akerlof (1970)). Additional assumptions should then be made in the basic setup that will allow for signalling opportunities to exist. Miglo et al (2018) consider a situation with two consecutive rounds of financing and argue that reward-based crowdfunding ${ }^{6}$ can be used as a signal of quality when asymmetric information concerns either the cost of production or product quality. Intuitively reward-based crowdfunding resembles debt financing where funders know exactly what they are getting in exchange for their funds while payoffs under equity-based crowdfunding on the other hand are intuitively more sensitive to the quality of information about a firm's future earnings so reward-based crowdfunding can be used by entrepreneurs to signal their quality. Miglo et al (2018) argue that low-quality firms

over-a-new-leaf-as-crowdfunding-gains-ground-1.149539

http://www.bbc.co.uk/news/magazine-21932675

${ }^{2}$ https://crowdfundcampus.com/blog/2017/01/crowdfunding-in-2017-three-key-trends/

${ }^{3}$ See, for example, https://crowdfundcampus.com/blog/2017/01/crowdfunding-in-2017three-key-trends/

${ }^{4}$ Moritz and Block (2014) and Kuppuswamy and Bayus (2015a) provide a review of the literature in this field. For international aspects of crowdfunding see, for example, Gabison (2015) or Hatfield (2017).

${ }^{5}$ See, for example, Haiward et al (2006) and Everett and Fairchild (2015).

${ }^{6}$ See, for example, Giudici, Nava, Rossi Lamastra and Verecondo (2012) for definitions of the different types of crowdfunding. 
may not be interested in mimicking high-quality firms when the latter use AON (all-or-nothing) campaigns because of the risk of their projects failing can be costly in the second period. ${ }^{7}$

Alternatively, Belleflamme, Lambert and Schwienbacher (2014) add nonmonetary benefits (social benefits for funders from participating in crowdfunding) in the basic set-up and argue that equity-based crowdfunding can provide a slightly higher value to an entrepreneur under asymmetric information than it can under symmetric information. They also argue that asymmetric information reduces an entrepreneur's value for reward-based crowdfunding. Uncertainty about a project's quality only partly hurts investors under equity-based crowdfunding since they count on long-term benefits but has a much more substantial negative impact on them under reward-based crowdfunding. As the authors mentioned, they did not consider a full asymmetric information model where entrepreneurs can choose between two crowdfunding methods. In this paper we consider an asymmetric information case where both types of crowdfunding can be used and no non-monetary benefits exist. ${ }^{8}$ It contributes to this line of literature by adding entrepreneurial overconfidence in the basic one-period set-up when analyzing the role of asymmetric information for crowdfunding decisions.

Similar to Belleflamme et al (2014) we focus on the two types of crowdfunding: reward-based crowdfunding and equity-based crowdfunding. ${ }^{9}$ Our model includes both the financing and production decision of the firm reflecting the fact that crowdfunding is an area where production decisions and finance are closely connected. The crowdfunding method choice directly and indirectly affects the development of a project and its promotion, production scale and price decisions. The model includes overconfident entrepreneurs but also contains asymmetric information between entrepreneurs and funders regarding product quality. When information is symmetric but the entrepreneur is overconfident we first argue that if a firm uses reward-based crowdfunding in the form of AON, the firm has a higher chance of failure compared to a rational entrepreneur. This result is consistent with some recent empirical evidence as will be discussed below. We then consider equity-based crowdfunding. We find that equity-based crowdfunding can provide more profits for the firm than rewardbased crowdfunding. The difference between these two types of crowdfunding is that equity-based crowdfunding involves funders that have a long-term in-

\footnotetext{
${ }^{7}$ The AON model involves the entrepreneurial firm setting a fundraising goal and keeping nothing unless the goal is achieved. This contrasts the "Keep-It-All" (KIA) model involves the entrepreneurial firm setting a fundraising goal and keeping the entire amount raised, regardless of whether or not they meet their goal.

${ }^{8}$ As was mentioned in Miglo et al (2018), some research discovered that the role of such non-monetary benefits in crowdfunding is negligeable (see, for example, Cholakova and Bart (2015)). In our model, there are no non-monetary benefits from crowdfunding: its benefits arise from natural features of crowdfunding such as market feedback, close connections between production and financing, asymmetric information etc.

${ }^{9}$ The addition of debt-based crowdfunding does not add significantly new results to our model. Most existing theoretical literature on crowdfunding often considers reward-based and equity-based crowdfunding separately from debt-based crowdfunding. One of the reasons for this seems to be that the founders' objectives are quite different in these scenarios (see, for example, Hildebrand, Puri, and Rocholl (2014)).
} 
terest in the company/product. So when the firm sells shares to this kind of funder, the price of shares reflects the firm's long-term potential. The funders should anticipate the future spot market decision from the entrepreneur unlike under reward-based crowdfunding where the funders and the entrepreneur essentially interact only once (during the pre-sale/ (crowdfunding) stage). So with equity-based crowdfunding the funders anticipate the entrepreneurs' overconfident product decision which helps them mitigate the negative effect of the entrepreneurial overconfidence at the prodcution stage.

We also consider a scenario where the entrepreneur learns from his experience. Under equity-based crowdfunding, the entrepreneur has an opportunity to learn from the market valuation of firm's shares before making production decisions. We argue that if this takes place indeed, equity-based crowdfunding is also more efficient than reward-based crowdfunding since the entrepreneur will become more rational by the time the production decision must be made. This is consistent with the idea that equity-based crowdfunding is a better tool in terms of market feedback than reward-based crowdfunding (see, for example, Arkrot, Unger and Ahlstrom (2017)).

Next we consider the case with asymmetric information and overconfident entrepreneurs. Our model predicts that high-quality firms may use equity-based crowdfunding in equilibrium which contrasts the results in Miglo et al (2018), which only used asymmetric information. The result is also quite surprising with regard to traditional theories of financing. Pecking-order theory (Myers and Majluf, 1984), for example, predicts that equity should only be used as a last resort. Firms issuing equity will be undervalued. Consequently only firms with low expected performance may issue equity. Similarly signalling theory usually suggests that debt issues can be used as a positive signal of firm performance (Leland and Pyle, 1977) as opposed to equity issues (negative signal).

In our model there are two firm types: high and low quality. When the entrepreneurs of both firms are rational, no separating equilibrium exists where the high-quality firm uses equity-based crowdfunding, which is consistent with traditional theories. However, when one firm has an overconfident entrepreneur a separating equilibrium can exist where the high-quality firm uses equity-based crowdfunding. If the degree of overconfidence is sufficiently high, the market anticipates this and reduces the market value of the firm's shares, which leads to a decrease in entrepreneur's profit. So the low-quality firm may avoid mimicking the high-quality firm because the market "discount" for the manager's overconfidence can overweigh the benefits from "misguiding" the market in terms of the firm's quality. We also show that a separating equilibrium where the highquality firm uses reward-based crowdfunding still dominates the one where the high-quality firm uses equity-based crowdfunding. This is because the former may not exist even if the level of overconfidence is high. For example if entrepreneurs learn from shares sale our model predicts that the firm can achieve the level of profits similar to the case with rational entrepreneurs and consequently mimicking the high-quality firm could lead to a higher payoff for the low-quality compared to its equilibrium payoff and hence a separating equilibrium where the high-quality firm uses equity-based crowdfunding does not exist very confusing 
sentence. This does not happen with reward-based crowdfunding. A separating equilibrium always exists when the level of overconfidence is sufficiently high.

Lin and Pursiainen (2018) test whether the observed gender differences in crowdfunding performance results from male entrepreneurs' relative overconfidence by analyzing a near-comprehensive sample of Kickstarter campaigns launched by individual entrepreneurs in the U.S. They find that male entrepreneurs tend to overestimate the potential demand for their products and hence set higher goal amounts, resulting in more frequent failures. In contrast, female entrepreneurs' campaigns are more likely to succeed and achieve higher pledged amounts relative to campaign goals. In successive campaigns, male entrepreneurs' success rates and goal amounts converge toward those of female entrepreneurs because entrepreneurial experience mitigates the effects of overconfidence.

To the best of our knowledge, the only other paper that use behavioral finance approach for crowdfunding is the following. Fairchild, Liu, and Yao (2017) analyze the moral hazard-based model of the entrepreneur's choice between venture capital financing and crowdfunding. Venture capital provides 'network benefits', and crowdfunding-investors demonstrate behavioural/emotional excitement when investing through the platform. The entrepreneur is overconfident regarding the potential benefits of the venture capital network and the level of crowd excitement. It is shown that a higher level of overconfidence usually benefits venture capital financing. In contrast to Fairchild et al (2017), in our model the entrepreneur's overconfidence concerns a firm's major information such as the demand for the firm's products. Also they do not consider ex-ante asymmetric information between entrepreneurs and funders.

The rest of the paper is organized as follows. Section 2 presents the basic model and some results for situations when the entrepreneur is overconfident but the information is symmetric. Section 3 discusses the case of asymmetric information. Section 4 discusses the model's robustness and its potential extensions. Section 5 discusses the consistency of the model's predictions with observed empirical evidence and Section 6 is a conclusion to the study.

\section{Basic Model}

An entrepreneurial firm has monopoly power over its innovative product or service. If the firm produces $q$ units, it costs $c q$ in total. ${ }^{10}$ The demand for the good is given by the inverse demand function $q=a-p \cdot{ }^{11}$ Under reward-based

\footnotetext{
${ }^{10}$ Section 5 discusses model extensions and robustness with regard to the inclusion of fixed costs.

${ }^{11}$ This approach for modelling the demand is based on Miglo et al (2018). Just as in that paper our focus is not on price discrimination between consumers. For further explanations see Miglo et al (2018). Some papers use the approach where, for example, there are individual customers with different demand functions (see, for example, Belleflamme et al (2014) and $\mathrm{Hu}, \mathrm{Li}$ and Shi (2014)). Note that without additonal assumptions, the fact of modelling individual consumers often leads to a similar framework. For example, assume that a potential consumer's surplus from buying the product is $v-p$, where $p$ is the price and $v$ is the consumer's
} 
crowdfunding the firm selects the price $p$ and collects pre-orders for its future product or service. Under equity-based crowdfunding, the firm sells a fraction $\alpha$ of the firm. Funders and entrepreneurs are assumed to be risk-neutral and the risk-free interest rate is 0 . If the firm selects reward-based crowdfunding, it has two options: KIA (keep-it-all) or AON (all-or-nothing). If AON is selected, a threshold $T$ is set, $T>0$. If the amount of funds raised during the pre-sale campaign is less than $T$, the firm is liquidated. The firm acts in the interest of the founder(s) (whom we will call the entrepreneur) and maximizes his expected profit. In addition, the entrepreneur can be overconfident. It means he thinks that the demand for firm's product equals $q=a+\varepsilon-p$, where $\varepsilon$ reflects the extent of the entrepreneur's overconfidence, $\varepsilon \geq 0$. A high $\varepsilon$ means that the entrepreneur significantly overestimates the expected demand for the firm's product/service.

Our model closely follows Belleflamme et al (2014) and Miglo et al (2018). Unlike Belleflamme et al (2014), our model does not have any non-monetary benefits for crowdfunders. Our main focus is the role of the entrepreneur's overconfidence on the crowdfunding outcome. Overconfidence is not part of either of the above mentioned papers.

The timing of events is as follows:

1. Firm selects financing strategy: KIA, AON or equity-based crowdfunding. If $\mathrm{AON}$ is selected, the firm selects $T$.

2. If equity-based crowdfunding is selected, the firm selects $\alpha$. The market value of shares $M$ is determined.

3. Firm selects $p$ and $q$ is determined.

4. If $\mathrm{AON}$ is selected and $p q<T$, the firm is liquidated.

5. If equity-based crowdfunding is selected and $M<c q$, the firm is liquidated.

6. The project is launched and the entrepreneur collects profit.

Under symmetric information with rational entrepreneurs $(\varepsilon=0)$, the solution is the same as in Miglo and Miglo (2018). More specifically we have the following. If $a \geq c: 1$ )

$$
p=\frac{a+c}{2}
$$

2) the firm is indifferent between the different types of crowdfunding; 2) if AON is selected, $\left.T \leq \frac{a^{2}-c^{2}}{4} ; 3\right)$ if equity-based crowdfunding is selected, $M=$

product valuation. Each consumer only needs one unit of the product/service. The valuation from consuming an extra-unit is zero. Consumers buy/order the product/service as long as they have a non-negative surplus $v-p$, where $p$ is the price. $v$ is uniformly distributed between 0 and $a$. In this setting if the price equals $p$, all consumers with $v$ greater than $p$ will be buying the product and the demand is then $q=a-p$ like in our model. Section 4 discusses the model's robustness with regard to changes in the demand functions. 
$\frac{c(a-c)}{2}$ and $\alpha=\frac{2 c}{a+c}$. If $a<c$, the project will not be undertaken. For brevity we omit the formal proof (see Miglo et al (2018)). ${ }^{12}$ These results are not surprising given that in the absence of any financial market imperfections every type of financing should have the same result (similar to the Modigliani-Miller proposition (1958)).

Now consider the case when the entrepreneur is overconfident.

\subsection{Reward-Based Crowdfunding: KIA}

The firm maximizes the entrepreneur's expected profit $\Pi=p q-c q=(p-c) q=$ $(p-c)(a+\varepsilon-p)$ subject to $p \geq c$ (otherwise the funds raised will not cover the production cost). So from the entrepreneur's point of view the optimal price is:

$$
p=\frac{a+\varepsilon+c}{2}
$$

With this price, the firm's expected profit equals

$$
\Pi=\left(\frac{a+\varepsilon+c}{2}-c\right)\left(a-\frac{a+\varepsilon+c}{2}\right)=\frac{(a-c)^{2}-\varepsilon^{2}}{4}
$$

Note that in (3) the demand equals $q=a-p$. The entrepreneur, however, thinks that $q=a+\varepsilon-p$ so he expects the following amount of profit:

$$
\left(\frac{a+\varepsilon+c}{2}-c\right)\left(a+\varepsilon-\frac{a+\varepsilon+c}{2}\right)=\frac{(a+\varepsilon-c)^{2}}{4}
$$

This is greater than (3) because $\varepsilon>0$. Note that $p \geq c$ because $a \geq c$ and $\varepsilon>0$.

\subsection{Reward-Based Crowdfunding: AON}

The firm chooses $T$ and $p$ to maximize $\Pi$ where $\Pi=(p-c)(a+\varepsilon-p)$ if $p q=p(a+\varepsilon-p) \geq T$ and $\Pi=0$ if $p q=p(a+\varepsilon-p)<T$.

The solution is any $T$ such as $T \leq p(a-p)$ where $p=\frac{a+\varepsilon+c}{2}$, which implies

$$
T \leq \frac{(a+\varepsilon)^{2}-c^{2}}{4}
$$

The firm's expected sales are: $p(a-p)=\frac{a+\varepsilon+c}{2}\left(a-\frac{a+\varepsilon+c}{2}\right)=\frac{a^{2}-(c+\varepsilon)^{2}}{4}$, which is less than the amount expected by the entrepreneur: $\frac{(a+\varepsilon)^{2}-c^{2}}{4}$. If $T \leq \frac{a^{2}-(c+\varepsilon)^{2}}{4}$, the firm's profit equals

$$
\Pi=\left(\frac{a+\varepsilon+c}{2}-c\right)\left(a-\frac{a+\varepsilon+c}{2}\right)=\frac{(a-c)^{2}-\varepsilon^{2}}{4}
$$

\footnotetext{
${ }^{12}$ Technically, a minor difference exists between this paper and Miglo et al (2018). In the former the firm is allowed to keep free cash received from crowdfunding and not necessarily use it in production. In this paper all cash will be invested. This simplifies calculations without affecting any ideas.
} 
This is less than the amount expected by the entrepreneur: $(p-c)(a+\varepsilon-p)=$ $\left(\frac{a+\varepsilon+c}{2}-c\right)\left(a+\varepsilon-\frac{a+\varepsilon+c}{2}\right)=\frac{(a+\varepsilon-c)^{2}}{4}$. If

$$
T>\frac{a^{2}-(c+\varepsilon)^{2}}{4}
$$

, the project will fail. If it is assumed that the entrepreneur can select any $T$ as long as it satisfies the optimality conditions from his point of view, we get the following result.

Lemma 1. An overconfident entrepreneur fails more often than a rational entrepreneur.

The proof follows from noting that the right side of $(5)$ is greater than that of (6) so the entrepreneur can select $T$ such that $\frac{a^{2}-(c+\varepsilon)^{2}}{4}<T \leq \frac{(a+\varepsilon)^{2}-c^{2}}{4}$, and then he thinks that the threshold will be reached when in reality it will not be.

\subsection{Equity-Based Crowdfunding}

After shares are sold, the firm choses $q$ to maximize the entrepreneur's expected profit. Two cases are possible. Either the entrepreneur ignores the information from the market valuation of shares and remains overconfident (this case will be considered in section 2.3.1) or he learns from it (this case will be considered in section 2.3.2). Chen et al (2018) provide a discussion of issues related to entrepreneurial overconfidence and learning. It still remains puzzling whether or not entrepreneurs learn from experience. Examples of issues related to this question include small samples (March, Sproull, and Tamuz (1991)) and the challenges of causal inference when feedback is unreliable (March and Olsen (1976)). Brehmer (1980) noted that people do not always improve their judgment with experience. Individual biases related to overconfidence undermine the efficacy with which inference is drawn from experience (Hayward, Shepherd, and Griffin (2006), Åstebro et al. (2014), Cain, Moore, and Haran (2015)). Some recent research, however, argues that overconfidence can even improve learning in some cases. ${ }^{13}$

\subsubsection{Entrepreneur ignores information from the market valuation of shares and remain overconfident}

Proposition 1. Equity-based crowdfunding leads to higher expected profit than reward-based crowdfunding. In some cases the outcome is the same as in the case with rational entrepreneur.

Proof. See Appendix.

Below we show an illustration of some cases considered in the proof of Proposition 1. One possible scenario is the following. The entrepreneur offers $\alpha$ that satisfies

$$
\frac{2 c}{a+\varepsilon+c} \leq \alpha \leq \frac{2 c}{a-\varepsilon+c}
$$

\footnotetext{
${ }^{13}$ See, for example, Puiu (2016).
} 
and expects that $M$ satisfies

$$
M=\frac{\alpha(a+\varepsilon-c)^{2}}{4(1-\alpha)}
$$

The reason why the entrepreneur can offer any $\alpha$ that satisfies (7) is because if the entrepreneur's expectations about $M$ were true, his payoff would not depend on $\alpha$. Indeed the entrepreneur's payoff (from his point of view) equals

$$
(1-\alpha)(p q+M-c q)=(1-\alpha)((a+\varepsilon-q) q+M-c q)
$$

Here $q$ optimizes the firm's proft after shares are sold. Hence $q=\frac{a+\varepsilon-c}{2}$. If $M$ were to be equal to (8) then the entrepreneur's payoff would be equal to $(1-\alpha)\left(\frac{(a+\varepsilon-c)^{2}}{4}+\frac{\alpha(a+\varepsilon-c)^{2}}{4(1-\alpha)}\right)=\frac{(a+\varepsilon-c)^{2}}{4}$ and it would not depend on $\alpha$. Note also that this equals (4) meaning that the entreprneur expectes athe same profit under both methods of crowdfunding.

However, after offering $\alpha$ for sale, the entrepreneur will soon find out that $M$ equals

$$
M=a c-\frac{c^{2}}{\alpha}
$$

Then the firm is not able to produce an optimal quantity from the entrepreneur's point of view and we have $q=\frac{M}{c}=a-\frac{c}{\alpha}$ and $p=\varepsilon+\frac{c}{\alpha}$. The firm's expected profit equals

$$
(1-\alpha) q p=(1-\alpha)\left(a-\frac{c}{\alpha}\right) \frac{c}{\alpha}
$$

Here $p=a-q=\frac{c}{\alpha}$. The funders' payoff equals $\alpha\left(a-\frac{c}{\alpha}\right) \frac{c}{\alpha}=a c-\frac{c^{2}}{\alpha}=M$.

(10) is greater than (3) when $\alpha$ satisfies (7). Indeed the derivative of (10) first increases in $\alpha$ and then decreases. In the corners (i.e. when $\alpha=\frac{2 c}{a+\varepsilon+c}$ or $\frac{2 c}{a-\varepsilon+c}$ ) (10) equals (3) but in the middle it is greater. For example, when $\alpha=\frac{2 c}{a+c}$, the firm's profit equals $\frac{(a-c)^{2}}{4}$.

The intuition behind Proposition 1 is as follows. Equity-based crowdfunding has two parts. On one hand, funders (who dont know the firm's type) buy shares and make investments. The degree of overconfidence affects the fraction of equity offered to funders. The higher the degree of overconfidence, the smaller the fraction offered. On the other hand, after shares are sold, the firm sells their product to their customers. The funders know the future demand functions which cannot be changed (unlike mistakes in entrepreneurial decisions due to overconfidence) and therefore the funders can strategically anticipate the likely scenario and predict the entrepreneur's behavior. This is different from selling the product using pre-orders like in the case of reward-based crowdfunding. In this case the whole process is just a one-time interaction between the entrepreneur and the funders so there is no room to smooth entrepreneurial mistakes in the future. The funders understand this and so the firm's profit is lower than in the case of equity-based crowdfunding.

Quite paradoxically, at the moment when the entrpereneur makes his decision, he does not realize that equity-based crowdfunding leads to a higher payoff 
becasue he thinks it should be equal to $\frac{(a+\varepsilon-c)^{2}}{4}$ which is the same amount as in $(4)$.

\subsubsection{Entrepreneur learns from the market valuation of shares.}

The difference between the case with learning and the case without learning can be attributed to the origin of overconfidence (see, for example, Chen et al (2018)). In the case with learning one can assume that the entrepreneur is quite a rational person but he probably is the subject of bad information or is facing the problem of lack of objective information at the beginning of his project and this is the main reason for his/her overconfidence. Once he realized this after observing the demand for shares, he makes all corrections immediately. In the case without learning however one can think, for example, that the origin of overconfidence is more psychological and is based on personality. Here the entrepreneur is less rational and even after observing the demand for shares and understanding that something is wrong compared to his initial plans he would think that it happened for some unexpected or even hazardous factors and so nothing serious should be changed in the decision-making process.

Proposition 1 holds for the case with learning as well.

Below we show an illustration of some cases considered in the proof of Proposition 1 for the case with learning. One possible scenario is the following. The entrepreneur offers

$$
\alpha>\frac{2 c}{a-\varepsilon+c}
$$

and expects that $M$ satisfies (8). This is similar to the previous case since the entrepreneur is overconfident when the firm sells shares. Also similarly, the entrepreneur can offer any $\alpha$ that satisfies (11) because if the entrepreneur's expectations about $M$ were true, then his payoff equals $\frac{(a+\varepsilon-c)^{2}}{4}$ and it does not depend on $\alpha$.

However, after offering $\alpha$ for sale, the entrepreneur will soon find out that $M$ equals

$$
M=\frac{\alpha(a-c)^{2}}{4(1-\alpha)}
$$

Then the firm is able to produce an optimal quantity from the entrepreneur's point of view and we have $q=\frac{a-c}{2}$ and $p=\frac{a+c}{2}$. The firm's expected profit equals

$$
(1-\alpha)\left(\frac{(a-c)^{2}}{4}+M\right)
$$

Since $M$ is determined according to (12), this equals $\frac{(a-c)^{2}}{4}$. This is greater than (3). The funders' payoff equals $\alpha\left(\frac{(a-c)^{2}}{4}+M\right)=M$ so the funder does not loose any money.

As was shown, in some cases, the firm's payoff under equity-based crowdfunding is the same as under reward-based crowdfunding but under some scenarios it can be higher. In fact, in some scenarios the entreprneur's payoff is the 
same as it would be if he was completely rational. It is consistent with Fairchild (2005) in that the overconfidence does not necessarily hurt entrepreneurs.

\section{Asymmetric information and overconfident en- trepreneur}

In this section we analyze the model where entrepreneurs are overconfident and asymmetric information exists between entrepreneurs and funders. Suppose that the firm can be either a low-quality firm (denoted $l$ ) or a high-quality firm (denoted $h$ ). More specifically, suppose that $a$ is either equal to $a_{l}$ or $a_{h}$ and $a_{l}<a_{h}$. Initially the firm's type (the value of $a$ ) is determined and becomes known to the entrepreneur. Also let us assume that the fraction of type $h$ firms equals $x$. Also we suppose that the entrepreneur of one firm is overconfident and the second firm has an unbiased entrepreneur and the market does not know the firm's type. ${ }^{14,15}$ If the entrepreneur of type $j$ is overconfident, he thinks that the firm's demand equals $q_{j}=a_{j}+\varepsilon-p, j=l, h$. If the entrepreneur of firm $l$ is overconfident, one may have a situation where the entrepreneur of firm $l$ thinks that his firm has better quality than another firm while it is not the case in reality.

The timing of events is as follows:

1. The firm's type is revealed to the entrepreneur.

2. Firm selects financing strategy: reward-based crowdfunding ${ }^{16}$ or equitybased crowdfunding.

3. If equity-based crowfunding was selected, the firm selects $\alpha$. The market value of shares $M$ is determined. The firm produces $q, q \leq M / c$. The price is determined, $p=a-q$.

4. If reward-based crowdfunding was selected, the firm selects $p, p \geq c$. The demand for the product is determined, $q=a-p$.

An equilibrium is defined as a situation where no firm type has an incentive to deviate. To set some benchmark results we start the analysis with the case $\varepsilon=0$. It will be shown that in this case a separating equilibrium does not exist, i.e. the low-quality firm always has an incentive to mimick the high-quality firm. Under

\footnotetext{
${ }^{14}$ In Section 5 we discuss the case when all entrepreneurs are overconfident. Also note that the emipirical research shows that not all entrepreneurs are overconfident (see, among others, Lin et al (2018)). Same holds when one considers the managers of large companies (see, for example, Malmendier et al (2013)).

${ }^{15} \mathrm{Ji}$ and Miglo (2018) analyze a corporate finance model with asymmetric information and overconfident managers. They argue that if the managers of a high-quality firm are overconfident, the model's results are similar to the case with rational managers.

${ }^{16}$ In this section there is no difference between AON and KIA since asymmetric information is related to the cost of production and there is no demand uncertainty. When using AON, the firm should just follow the rule regarding the choice of $T$ established in Lemma 1.
} 
equity-based crowdfunding, the price that potential investors will be paying for a fraction of a firm's shares depends on their beliefs about the product's quality. This leads to the point that a separating equilibrium (an equilibrium where firms select different strategies) does not exist. If the high-quality type chooses equity-based crowdfunding, it will be mimicked by the low-quality type who will benefit from the higher values of shares. This result is typical for basic models with asymmetric information beginning with Akerloff (1970). Similar results can be found in classic papers on financing under asymmetric information (e.g. Myers and Majluf (1984)) and in some other papers on crowdfunding with asymmetric information (Miglo et al (2018)). Same logic applies to reward-based crowdfunding because if funders believe the firm is high-quality, the pre-sale price is higher.

Proposition 2. Suppose $\varepsilon=0$. A separating equilibrium does not exist. ${ }^{17}$

Proof. Consider a situation where $l$ selects reward-based crowdfunding and $h$ selects equity-based crowdfunding. If a separating equilibrium exists, the market beliefs about the firm's type are unbiased for each type of firm. Therefore we have (all calculations are based on the symmetric information case for each type described in Section 2):

$$
\begin{aligned}
\Pi_{h} & =\frac{\left(a_{h}-c\right)^{2}}{4} \\
\Pi_{l} & =\frac{\left(a_{l}-c\right)^{2}}{4}
\end{aligned}
$$

where $\Pi_{j}$ is the equilibrium profit of type $j$. Also we have (as follows from Lemma 1):

$$
\begin{gathered}
\alpha_{h}=\frac{2 c}{a_{h}+c} \\
M_{h}=\frac{c\left(a_{h}-c\right)}{2}
\end{gathered}
$$

Suppose that $l$ mimics $h$ and chooses equity-based crowdfunding instead. l's profit $\Pi_{l h}$ then equals

$$
\Pi_{l h}=\left(1-\alpha_{h}\right)\left(p q+M_{h}-c_{l} q\right)
$$

After shares are sold, the entrepreneur will select $p$ and $q$ that maximize the value in the second bracket: $p=\frac{a_{l}+c}{2}$ and $q=\frac{a_{l}-c}{2}$. Note that these are the same values as under symmetric information for type $l$. However, the diffewrence here is that when $l$ mimicks $h$, it has to sell a smaller stake of equity in the firm compared to the symmetric information case and he also gets more money because $a_{h}>a_{l}$. This means that $l$ has a higher payoff than (14) so it will mimick $h$ and such an equilibrium does not exist.

Now consider a situation where $h$ selects reward-based crowdfunding and $l$ selects equity-based crowdfunding. The payoffs again are determined according

\footnotetext{
${ }^{17}$ Based on Miglo et al (2018).
} 
to (13) and (14). Suppose that $l$ mimics $h$ and chooses reward-based crowdfunding instead. Using similar reasoning one can show that $l$ 's profit $\Pi_{l h}$ equals

$$
\Pi_{l h}=\frac{\left(a_{h}-c\right)^{2}}{4}
$$

This is greater than (14). This means that such an equilibrium does not exist.

Next we analyze the pooling equilibria. We define a pooling equilbrium as one where both types of firms select the same strategy. We will also check that the off-equilibrium beliefs of market participants survive the intuitive criterion by Cho-Kreps (1987). This condition means that the market off-equilibrium beliefs are reasonable in the sense that if for any firm type its maximal payoff from deviation is not greater than its equilibrium payoff then the market should place the probability 0 on possible deviations of this type. The definitions above are consistent with the standard perfect bayesian equilibrium definition (see, for instance, Fudenberg and Tirole, 1991) with the addition of an intuitive criterion that is quite common in these types of games (see, for instance, Nachman and Noe, 1994). If multiple pooling equiliria exist we will use the mispricing criterion to indicate the one that is most likely to exist. We use the standard concept of mispricing that can be found, for example, in Nachman and Noe (1994). The magnitude of mispricing in a given equilibrium is equal to that of the undervalued type(s). The overvaluation of the overvalued type(s) does not matter.

Proposition 3. 1) Pooling with equity-based crowdfunding is an equilibrium; 2) if pooling with reward-based crowdfunding exists, then mispricing is larger under that than under the pooling equilibria with equity-based crowdfunding.

Proof. See Appendix.

The idea behind Proposition 3 is simple. Equity-based crowdfunding has two parts. On one hand, funders (who dont know the firm's type) buy shares and make investments. On the other hand, after shares are sold, the firm sells its product to their customers. This part of the business is not affected by asymmetric information. In contrast under reward-based crowdfunding the funders order (buy) the product under asymmetric information. So the effect of asymmetric information is more pronounced under reward-based crowdfunding and the high-quality type is more affected in this case.

Now suppose that the entrepreneur of one firm is overconfident and the second firm has an unbiased entrepreneur and the market does not know the firm's type. We will show that: 1 ) a separating equilibrium can exist where the highquality firm uses equity-based crowdfunding. If the degree of overconfidence is high enough, the market anticipates this and as we know from Section 2, it will imply a significantly lower market value of shares and ultimately a significant decrease in the entrepreneur's profit; 2) a separating equilibrium where the high-quality firm uses reward-based crowdfunding dominates the one where high-quality firm uses equity-based crowdfunding. This is because the former may not exist even if the level of overconfidence is high. For example if entrepreneurs learn from the sale of shares then the firm can achieve a higher value than 
under reward-based crowdfunding and it also leads to a higher payoff for the low-quality firm if it decides to mimick the high-quality firm. It does not happen with reward-based crowdfunding. A separating equilibrium always exists when the level of overconfidence is high enough.

Proposition 4. 1) A separating equilibrium where the high-demand firm uses equity-based crowfunding may exist; 2) If a separating equilibrium where type $h$ selects equity-based crowdfunding and $l$ selects reward-based crowdfunding exists there also exists a separating equilibrium where type $h$ selects reward-based crowdfunding and type $l$ selects reward-based crowdfunding but not vice versa.

Proof. See Appendix.

The second part of Proposition 4 is consistent with the standard behavioral finance result about debt-equity choice with an overconfident entrepreneur (see, for example, Fairchild (2005)). This is also consistent with Miglo et all (2018) that reward-based crowdfunding dominates equity-based crowdfunding under asymmetric information. The first part of the proposition provides a new result because in the standard pecking-order theory equity is never issued by the highquality firm in a separating equilibrium.

Next we analyze the pooling equilibria.

Proposition 5. 1) If pooling with reward-based crowdfunding exists there also exists a pooling equilibrium with equity-based crowdfunding but not vice versa; 2) if pooling with reward-based crowdfunding exists, then mispricing is larger under that than under the pooling equilibria with equity-based crowdfunding.

Proof. Omitted for brevity. ${ }^{18}$

The idea behind Proposition 5 is simple. As was shown in Section 2, under equity-based crowdfunding the entrepreneur's payoff is higher than under reward-based crowdfunding. The same holds for the pooling equilibrium case so, based on the mispricing criterion, a pooling equilibrium with equity-based crowdfunding dominates one with reward-based crowdfunding.

\section{Implications}

Our paper has several implications for an entrepreneurial firm's choice of crowdfunding method and the role of entrepreneurial overconfidence and asymmetric information in these decisions. Lemma 1 implies that entrepreneurs that use AON fail more often than rational entrepreneurs. Although this prediction was not directly tested, it is consistent with the spirit of some literature. For example, Lin and Pursiainen (2018) find that male entrepreneurs (who also are more overconfident than female entrepreneurs) set higher goal amounts than female entrepreneurs and fail more frequently.

Propositon 1 implies that equity-based crowdfunding can provide a better value for an overconfident entrepreneur than reward-based crowdfunding. This is consistent with Fairchild (2005) that overconfidence does not necessarily hurt entrepreneurs. Also there is literature on equity-based crowdfunding

\footnotetext{
${ }^{18}$ Available upon request.
} 
that finds that it provides better market feedabck compared to reward-based crowdfunding (Arkrot et al (2017)). We obtained this result considering two scenarios: one where the entrepreneur remains overconfident after selling shares and the other one where he learns from selling shares. Under both scenarios the firm's profit is higher with equity-based crowdfunding than with reward-based crowdfunding. The difference between these two types of crowdfunding is that equity-based crowdfunding involves funders which have long-term interest in the company/product. So when the firm sells shares to this kind of funders, the price of shares reflects the firm's long-term potential. The funders should anticipate the future spot market decision from the entrepreneur unlike reward-based crowdfunding where the funders and the entrepreneur interact only once (during the pre-sale (crowdfunding) stage). So with equity-based crowdfunding the funders anticipate the entrepreneurs' overconfident product decision and it helps to mitigate the negative effect of entrepreneurial overconfidence at the prodcution stage. We also consider a scenario where the entrepreneur learns from his experience. Under equity-based crowdfunding, the entrepreneur has an opportunity to learn from the market valuation of the firm's shares before making any production decisions. We argue that if this takes place indeed, equity-based crowdfunding is also more efficient than reward-based crowdfunding since the entrepreneur will become more rational by the time the production decision must be made. It is consistent with the idea that equity-based creowdfunding is a better tool in terms of market feedback than reward-based crowdfunding.

Propositions 2 and 4 explain why under asymmetric information a highquality firm may be interested in using equity-based crowdfunding. This prediction has not been directly tested but is consistent with the spirit of the results found in Ahlers, Cumming, Guenther, and Schweizer (2015) and Mollick (2014) (that the firm's financing choice can serve as a signal of a project's quality). Generally speaking, issuing equity under asymmetric information is a puzzling phenomenon in the literature. It is mostly due to the Pecking-order theory result where equity represents an inferior security. ${ }^{19}$ To some extent, this result as well as the second parts of propositions 3 and 5 are consistent with the spirit of the results in Belleflamme et al (2014), which finds that equity-based crowdfunding has its benefits under asymmetric information. Proposition 4 though is consistent with the spirit of Miglo et al (2018) that reward-based crowdfunding can dominate equity-based crowdfunding in some cases under asymmetric information. However, our paper has new dimension related to entrepreneurs' overconfidence. Our result shows that a separating equilibrium exists and respectively singalling with crowdfunding can be used by high-quality firms when the degree of overconfidence is significantly large. It implies that signalling is pro-cyclical if one assumes that the degree of overconfidence is positively correlated with the economy's performance.

Equity-based crowdfunding provides useful feedback if entrepreneurs is over-

\footnotetext{
${ }^{19}$ For example, it is well-known in capital structure theory that asymmetric information damages equity financing more than debt financing and that equity financing cannot be used by a high-quality type as a signal of quality whereas in some cases debt financing can be used (Leland and Pyle (1977)).
} 
confident. We find that the value loss for the firm can be less than under reward-based crowdfunding. Hornuf and Neuenkirch (2017) analyze the factors of pricing in equity-based crowdfunding. It can be very informative.

In order for a separating equilibrium to exist where some firms use equitybased crowdfunding, the degree of overconfidence should be relatively high. If the degree of overconfidence is related to the degree of economic prosperity, it implies that equity-based crowdfunding is procyclical. This prediction has not yet been tested. Further research is expected. Interestingly, Zhang, Datta and Kannan (2015) find that crowdfunding can be seen as a substitute to bank loans in terms of overall dynamics. Previous literature found that debt financing is countercyclical (Choe, Masulis and Nanda (1993)). Note also the famous negative correlation between debt and profitability (Titman and Wessels (1988)) so the result in Zhang et al (2015) is indirectly consistent with our prediction.

\section{The model extensions and robustness}

Our model is the first that analyzes the role of entrepreneurial overconfidence in the choice between crowdfunding methods. As the reader can see from Sections 2 and 3, further extensions would make the paper much longer. We are certain that for future research many possible extensions are possible and would probably be related to adding more crowdfunding features into the model. ${ }^{20} \mathrm{In}$ the paper we find, for example, that under equity-based crowdfunding value is created when the entrepreneur is overconfident in two ways: the entrepreneur can learn from the crowdfunding campaign and make adjustments by the time the production decision is made (since the production decision is separate from the crowdfunding campaign) and the crowd can strategically anticipate the entrepreneur's behavior when valuing the shares offered for sale. One can extend the model by considering the case where under reward-based crowdfunding, individual demands are introduced, and the pre-sale stage and the spot-sale stage are considered separately and have different prices. However, opportunities for the firm to change the price are limited under reward-based crowdfunding as was argued in Belleflamme et al (2014) and Miglo et al (2018) because funders will rationally anticipate spot prices. If the prices are different, an arbitrage opportunity would exist so this cannot be an equilibirum situation. The equitlibrium price should then be equal to (1) (see also Footnote 11). This is consistent with the idea that there is less learning from reward-based crowdfunding than from equity-based crowdfunding (less market feedback) (see, for example, Arkrot et al (2017)). Hence explicitely adding two stages of crowdfunding (pre-sale and spot-sale) without adding any other new crowdfunding features would not change the result. New results may potentially arise if further complications and features are introduced. For example, one can consider two consecutive campaigns or introduce non-monetary benefits etc. These are

\footnotetext{
${ }^{20}$ Some exensions to a similar model are discussed in Miglo et al (2018) and some of this analysis can be applied to the present paper as well.
} 
definitely possible directions for future research, however, they are beyond the scope of the present paper.

\section{Conclusions}

This article considers a model of the choice between the different types of crowdfunding, which contains elements of the asymmetric information approach and behavioral finance (overconfident entrepreneurs). When entrepreneurs are rational and information between entrepreneurs and funders is symmetric, the firm is indifferent between the different types of crowdfunding. However, when an entrepreneur is overconfident, equity-based crowdfunding is more profitable than reward-based crowdfunding. This is because either the entrepreneur learns from the sales of shares before making production decisions or because the crowd anticipates the entrepreneur's behavior when valuing the shares offered for sale. These two natural mechanisms that mitigate overconfidence are less efficient with reward-based crowdfunding. This result is consistent with, for example, Arkrot et al (2017), which finds that equity-based crowdfunding provides more market feedback than reward-based crowdfuding. The model also predicts that an equilibrium can exist where high-quality firms use equity-based crowdfunding in equilibrium which contrasts the spirit of traditional results (for example the pecking-order theory) that state that equity is an inferior security. These traditional theories, however, generally assume rational managers. Our result also contrasts traditional behavioral finance literature (for example, Fairchild (2005)) where equity is not issued in equilibrium and has not yet been directly tested though it is consistent with the spirit of some empirical papers that find that entrepreneurs use equity-based crowdfunding as a signal of quality (for example, Ahlers et al (2015)).

\section{Appendix}

Proof of Proposition 1. After the firm's shares are sold, the entrepreneur choses $q$ to maximize

$$
(1-\alpha)(p q+M-c q)=(1-\alpha)((a+\varepsilon-q) q+M-c q)
$$

subject to

$$
q \leq M / c
$$

Two cases are possible. 1)

$$
M \geq \frac{c(a+\varepsilon-c)}{2}
$$

In this case the firm will be able to produce an optimal (from the entrepreneur's point of view) quantity of goods/services, i.e. it can select the $q$ that is the absolute maximum for (18) as the constraint (19) is not binding. It results in $q=\frac{a+\varepsilon-c}{2}$. The cost of production is $c q=\frac{c(a+\varepsilon-c)}{2} \leq M$ so the constraint (19) holds. 
The entrepreneur's expected profit equals

$$
(1-\alpha)((p-c) q+M)=(1-\alpha)\left(\left(\frac{a+\varepsilon+c}{2}-c\right)\left(a+\varepsilon-\frac{a+\varepsilon+c}{2}\right)+M\right)
$$

Note that the entrepreneur overestimates the demand for the firm's product, i.e. the entrepreneur thinks $q=a+\varepsilon-p$. After simplifications, it equals

$$
(1-\alpha)\left(\frac{(a+\varepsilon-c)^{2}}{4}+M\right)
$$

The funders' expected earnings should cover their investment cost $M$ or:

$$
\begin{aligned}
\alpha((p-c) q+M) & =\alpha\left(\left(\frac{a+\varepsilon+c}{2}-c\right)\left(a-\frac{a+\varepsilon+c}{2}\right)+\right. \\
+M) & =\alpha\left(\frac{(a-c)^{2}-\varepsilon^{2}}{4}+M\right)=M
\end{aligned}
$$

Note that here we have the rationally estimated demand: $q=a-p$. Solving for $M$ we have:

$$
M=\frac{\alpha\left((a-c)^{2}-\varepsilon^{2}\right)}{4(1-\alpha)}
$$

When selecting $\alpha$, the entrepreneur, however, thinks the funders' constraint (22) is different. He uses $q=a+\varepsilon-p$. In this case (22) becomes

$$
\begin{aligned}
\alpha((p-c) q+M) & =\alpha\left(\left(\frac{a+\varepsilon+c}{2}-c\right)\left(a+\varepsilon-\frac{a+\varepsilon+c}{2}\right)+\right. \\
+M) & =\alpha\left(\frac{(a+\varepsilon-c)^{2}}{4}+M\right)=M
\end{aligned}
$$

It implies:

$$
M=\frac{\alpha(a+\varepsilon-c)^{2}}{4(1-\alpha)}
$$

Consequently, from the entrepreneur's point of view (20) holds if:

$$
\frac{\alpha(a+\varepsilon-c)^{2}}{4(1-\alpha)} \geq \frac{c(a+\varepsilon-c)}{2}
$$

or

$$
\frac{\alpha(a+\varepsilon-c)}{2(1-\alpha)} \geq c
$$

So the entrepreneur thinks that in order for (20) to hold, he needs to offer $\alpha$ such that

$$
\alpha \geq \frac{2 c}{a+\varepsilon+c}
$$

Objectively, however, he should offer $\alpha$ such that the following holds (it follows from (20) and (23)):

$$
\frac{\alpha\left((a-c)^{2}-\varepsilon^{2}\right)}{4(1-\alpha)} \geq \frac{c(a+\varepsilon-c)}{2}
$$


It implies:

$$
\alpha \geq \frac{2 c(a+\varepsilon-c)}{(a-c)^{2}-\varepsilon^{2}+2 c(a+\varepsilon-c)}=\frac{2 c}{a-\varepsilon+c}
$$

Next note that the right side of (26) is smaller than that of (27). Therefore it is possible to have a situation where the entrepreneur thinks that (20) holds while it does not in reality. It is the case for the following $\alpha$ :

$$
\frac{2 c}{a+\varepsilon+c} \leq \alpha \leq \frac{2 c}{a-\varepsilon+c}
$$

From the entrepreneur's point of view any $\alpha$ can work as long as (26) holds. If we substitute (23) into (21) it becomes $(1-\alpha)\left(\frac{(a+\varepsilon-c)^{2}}{4}+\frac{\alpha(a+\varepsilon-c)^{2}}{4(1-\alpha)}\right)$ and it does not depend on $\alpha$. Consider two cases. 1. Suppose the entrepreneur selects the $\alpha$ that satisfies (28) and thinks that his expected profit (after substituting (25) into $(21)$ ) equals $\frac{(a+\varepsilon-c)^{2}}{4}$. However, in this case (20) does not hold as was shown above. The market participants realize that (20) never holds and therefore they will not evaluate shares offered by the entrepreneur using condition (23) and will provide smaller amount of $M$. So this case does not work. If the entrepreneur offers $\alpha$ according to (28), either (20) or (23) will not hold. We will discuss a possible scenario with (28) later.

2. Suppose the entrepreneur selects $\alpha>\frac{2 c}{a-\varepsilon+c}$. In this case $M$ is determined according to (23). The entrepreneur will select $q=\frac{a+\varepsilon-c}{2}$ and the firm's expected earnings are:

$$
\begin{aligned}
(1-\alpha)((p-c) q+M) & =(1-\alpha)\left(\left(\frac{a+\varepsilon+c}{2}-c\right)\left(a-\frac{a+\varepsilon+c}{2}\right)+\right. \\
+M) & =(1-\alpha)\left(\frac{(a-c)^{2}-\varepsilon^{2}}{4}+M\right)
\end{aligned}
$$

Since $M$ is determined according to $(23),(29)$ equals $\frac{(a-c)^{2}-\varepsilon^{2}}{4}$.

2)

$$
M<\frac{c(a+\varepsilon-c)}{2}
$$

In this case the firm will not be able to produce an optimal quantity of goods/services from the entrepreneur's point of view. We have $q=\frac{M}{c}$ (as long as $p \geq c$, the firm will produce as much quantity as possible) and $p=a+\varepsilon-\frac{M}{c}$.

The entrepreneur's expected profit then equals

$$
(1-\alpha) \frac{M}{c}\left(a+\varepsilon-\frac{M}{c}\right)
$$

Note that the entrepreneur overestimates the demand for the firm's product, i.e. the entrepreneur thinks $q=a+\varepsilon-p$. The funders' expected earnings should cover their investment cost or:

$$
\alpha \frac{M}{c}\left(a-\frac{M}{c}\right)=M
$$


Note that here we have the rationally estimated demand: $q=a-p$. Solving for $M$ we have:

$$
M=a c-\frac{c^{2}}{\alpha}
$$

When selecting $\alpha$, the entrepreneur, however, thinks that the funders' constraint (32) is different. He uses $q=a+\varepsilon-p$. In this case (32) becomes

$$
\alpha \frac{M}{c}\left(a+\varepsilon-\frac{M}{c}\right)=M
$$

It implies:

$$
M=(a+\varepsilon) c-\frac{c^{2}}{\alpha}
$$

Substituting this into (30) we find:

$$
(a+\varepsilon) c-\frac{c^{2}}{\alpha}<\frac{c(a+\varepsilon-c)}{2}
$$

or

$$
\alpha<\frac{2 c}{a+\varepsilon+c}
$$

If (35) holds, (30) also holds. Indeed, if we substitute (33) into (30) we find:

$$
a c-\frac{c^{2}}{\alpha}<\frac{c(a+\varepsilon-c)}{2}
$$

It implies $\alpha<\frac{2 c}{a+\varepsilon-c}$. So the entrepreneur will offer a small enough fraction of equity for sale in order for (30) to hold. From (34), we have:

$$
\alpha=\frac{c^{2}}{(a+\varepsilon) c-M}
$$

Substituting this into (31), we find that the entrepreneur's expected profit equals:

$$
\frac{\left((a+\varepsilon) c-M-c^{2}\right) M}{c^{2}}
$$

From the entrepreneur point of view, this is less than the expected profit $\left(\frac{(a+\varepsilon-c)^{2}}{4}\right)$ in the case when $M \geq \frac{c(a+\varepsilon-c)}{2}$. So the entrepreneur will select one of the following options. 1. $\alpha$ satisfies (28) and the entrepreneur expects that $M$ satisfies (25) as was discussed previously. However, after offering $\alpha$ for sale, the entrepreneur will soon find out that $M$ equals (33) as was shown above. Then the firm is not able to produce an optimal quantity from the entrepreneur's point of view and we have $q=\frac{M}{c}=a-\frac{c}{\alpha}$ and $p=\varepsilon+\frac{c}{\alpha}$. The firm's expected profit equals

$$
(1-\alpha) q p=(1-\alpha)\left(a-\frac{c}{\alpha}\right) \frac{c}{\alpha}
$$

Here $p=a-q=\frac{c}{\alpha}$. 
This is greater than (3) when $\alpha$ satisfies (28). Indeed the derivative of (36) first increases in $\alpha$ and then decreases. In the corners (i.e. when $\alpha=\frac{2 c}{a+\varepsilon+c}$ or $\frac{2 c}{a-\varepsilon+c}$ ) (36) equals (3) but in the middle it is greater. For example, when $\alpha=\frac{2 c}{a+c}$, the firm's profit equals $\frac{(a-c)^{2}}{4}$.

2. $\alpha>\frac{2 c}{a-\varepsilon+c}$. In this case the firm's profit equals $\frac{(a-c)^{2}-\varepsilon^{2}}{4}$ as was argued earlier.

Now consider the case with learning. In this case the entrepreneur will fully realize that he was overconfident after observing the value of shares. Hence, when selecting $q$, the entrepreneur maximizes

$$
(1-\alpha)(q(a-q)+M-c q)
$$

subject to

$$
M \geq c q
$$

Note that in (37) the demand is given by $p=a-q$ reflecting the fact that the entrepreneur learns from the sales of shares the true value of $a$. Two cases are possible. 1)

$$
M \geq \frac{c(a-c)}{2}
$$

In this case the firm will be able to produce an optimal quantity of goods/services, i.e. it can select $q$ that is the absolute maximum for (37) as the constraint (38) is not binding. This $q$ equals $\frac{a-c}{2}$. The cost of production is $c q=\frac{c(a-c)}{2} \leq M$ so the constraint (38) holds if (39) holds.

The entrepreneur's expected profit equals

$$
(1-\alpha)\left(\frac{(a-c)^{2}}{4}+M\right)
$$

The funders' expected earnings should cover their investment cost or:

$$
\alpha\left(\frac{(a-c)^{2}}{4}+M\right)=M
$$

We have:

$$
M=\frac{\alpha(a-c)^{2}}{4(1-\alpha)}
$$

Before shares are sold, the entrepreneur, however, thinks (he does not anticipate learning at the beginning, i.e. before the shares are sold) that

$$
M=\frac{\alpha(a+\varepsilon-c)^{2}}{4(1-\alpha)}
$$

Note that it's the same situation as in the previous section where we considered the case without learning. Actually the condition (43) is taken from previous case analysis (see (25)).

Two cases are possible reflecting the implications of the difference between the entrepreneur's expectations before the shares are sold and reality. 
a.

$$
M \geq \frac{c(a+\varepsilon-c)}{2}
$$

(if this is the case, the entrepreneur would be able to produce the optimum quantity from his point of view). Note that the firm's profit from his point of view in this case is

$$
(1-\alpha)\left(\frac{(a+\varepsilon-c)^{2}}{4}+M\right)
$$

For this to be the case, the entrepreneur should offer $\alpha$ such that the following holds (it follows from (44) and (43)):

$$
\frac{\alpha(a+\varepsilon-c)^{2}}{4(1-\alpha)} \geq \frac{c(a+\varepsilon-c)}{2}
$$

So the entrepreneur thinks that in order for (44) to hold, he needs to offer $\alpha$ such that :

$$
\alpha \geq \frac{2 c}{a+\varepsilon+c}
$$

Objectively, however, he should offer $\alpha$ such that the following holds (it follows from (44) and (42)):

$$
\frac{\alpha(a-c)^{2}}{4(1-\alpha)} \geq \frac{c(a+\varepsilon-c)}{2}
$$

It implies:

$$
\alpha \geq \frac{2 c(a+\varepsilon-c)}{(a-c)^{2}+2 c(a+\varepsilon-c)}
$$

Next note that the right side of (46) is smaller than that of (47). ${ }^{21}$ Therefore it is possible to have a situation where the entrepreneur thinks that (44) holds while it is not in reality. It is the case for the following $\alpha$ :

$$
\frac{2 c}{a+\varepsilon+c} \leq \alpha \leq \frac{2 c(a+\varepsilon-c)}{(a-c)^{2}+2 c(a+\varepsilon-c)}
$$

From the entrepreneur's point of view any $\alpha$ can work as long as (46) holds. If we substitute $(43)$ into $(45)$ it becomes $(1-\alpha)\left(\frac{(a+\varepsilon-c)^{2}}{4}+\frac{\alpha(a+\varepsilon-c)^{2}}{4(1-\alpha)}\right)=\frac{(a+\varepsilon-c)^{2}}{4}$ and it does not depend on $\alpha$. Consider two cases. 1. Suppose the entrepreneur selects the $\alpha$ that satisfies (28) and thinks that his expected profit (after substituting (43) into (45)) equals $\frac{(a+\varepsilon-c)^{2}}{4}$. However, in this case (44) does not hold as was shown above. The market participants realize that (44) never holds and therefore they will not evaluate shares offered by the entrepreneur using condition (42) and will provide a smaller $M$. So this case does not work. If the entrepreneur offers $\alpha$ according to (28), either (44) or (42) will not hold. We will discuss a possible scenario with (28) later.

\footnotetext{
${ }^{21}$ Simple algebra implies that the difference between them depends on the sign of $(a-c)^{2}+$ $2 c(a+\varepsilon-c)-\left((a+\varepsilon)^{2}-c^{2}\right)$ which in turns depends on $2 c \varepsilon-2 a \varepsilon-\varepsilon^{2}$ which is negative because $a>c$.
} 
2. Suppose the entrepreneur selects $\alpha>\frac{2 c}{a-\varepsilon+c}$. In this case $M$ is determined according to (42). The entrepreneur will select $q=\frac{a-c}{2}$ and the firm's expected earnings are:

$$
(1-\alpha)\left(\frac{(a-c)^{2}}{4}+M\right)
$$

Since $M$ is determined according to (41), this equals $\frac{(a-c)^{2}}{4}$.

b.

$$
\frac{c(a-c)}{2} \leq M<\frac{c(a+\varepsilon-c)}{2}
$$

In this case the firm still will be able to produce an optimal quantity of goods/services, i.e. it can select the $q$ that is the absolute maximum for (37) as the constraint (38) is not binding. Before shares are sold, the entrepreneur, however, thinks that the optimal quantity will not be produced (because $M<\frac{c(a+\varepsilon-c)}{2}$ ). Therefore he thinks that the firm's profit equals

$$
(1-\alpha) \frac{M}{c}\left(a+\varepsilon-\frac{M}{c}\right)
$$

He also thinks that the funders' expected earnings should cover their investment cost or:

$$
\alpha \frac{M}{c}\left(a+\varepsilon-\frac{M}{c}\right)=M
$$

It implies:

$$
M=(a+\varepsilon) c-\frac{c^{2}}{\alpha}
$$

Therefore he thinks that he should offer $\alpha$ such that the following holds (it follows from (48) and (50)):

$$
\frac{c(a-c)}{2} \leq(a+\varepsilon) c-\frac{c^{2}}{\alpha} \leq \frac{c(a+\varepsilon-c)}{2}
$$

So the entrepreneur thinks that in order for (48) to hold, he needs to offer $\alpha$ such that :

$$
\frac{c^{2}}{(a+\varepsilon) c-\frac{c(a-c)}{2}} \leq \alpha \leq \frac{c^{2}}{(a+\varepsilon) c-\frac{c(a+\varepsilon-c)}{2}}
$$

or

$$
\frac{2 c}{a+2 \varepsilon+c} \leq \alpha \leq \frac{2 c}{a+\varepsilon+c}
$$

Objectively, however, he should offer $\alpha$ such that the following holds (it follows from (48) and (42)):

$$
\frac{c(a-c)}{2} \leq \frac{\alpha(a-c)^{2}}{4(1-\alpha)} \leq \frac{c(a+\varepsilon-c)}{2}
$$

It implies:

$$
\frac{2 c}{a+c} \leq \alpha \leq \frac{2 c(a+\varepsilon-c)}{2 c(a+\varepsilon-c)+(a-c)^{2}}
$$


Since the right side of (51) is smaller than the left side of (52), this case does not work. The market participants realize that (48) never holds and therefore they will not evaluate shares offered by the entrepreneur using condition (42).

2)

$$
M<\frac{c(a-c)}{2}
$$

In this case the firm will not be able to produce an optimal quantity of goods/services. We have $q=\frac{M}{c}$ (as long as $p \geq c$, the firm will produce as much quantity as possible) and $p=a-\frac{M}{c}$.

The entrepreneur's expected profit then equals

$$
(1-\alpha) \frac{M}{c}\left(a-\frac{M}{c}\right)
$$

The funders' expected earnings should cover their investment cost or:

$$
\alpha \frac{M}{c}\left(a-\frac{M}{c}\right)=M
$$

We have:

$$
\begin{aligned}
& \alpha=\frac{c^{2}}{a c-M} \\
& M=a c-\frac{c^{2}}{\alpha}
\end{aligned}
$$

When selecting $\alpha$, the entrepreneur, however, thinks that (see condition (50))

$$
M=(a+\varepsilon) c-\frac{c^{2}}{\alpha}
$$

Substituting this into (53) we find:

$$
(a+\varepsilon) c-\frac{c^{2}}{\alpha}<\frac{c(a-c)}{2}
$$

or

$$
\frac{a+2 \varepsilon+c}{2}<\frac{c}{\alpha}
$$

Then we have:

$$
\alpha<\frac{2 c}{a+2 \varepsilon+c}
$$

If (58) holds, (53) also holds. Indeed, if we substitute (56) into (53) we find:

$$
a c-\frac{c^{2}}{\alpha}<\frac{c(a-c)}{2}
$$

or

$$
\frac{a+c}{2}<\frac{c}{\alpha}
$$


It implies:

$$
\alpha<\frac{2 c}{a+c}
$$

If we compare the right side of (58) and that of (59) we find that the former is smaller. So the entrepreneur will offer a small enough fraction of equity for sale.

Substituting (57) into (54), we find that the entrepreneur's expected profit equals:

$$
\frac{\left((a+\varepsilon) c-M-c^{2}\right) M}{c^{2}}
$$

From the entrepreneur point of view, this is less than the expected profit $\left(\frac{(a+\varepsilon-c)^{2}}{4}\right)$ in the case when $M \geq \frac{c(a-c)}{2}$. So the entrepreneur will be following this strategy: $M=(a+\varepsilon) c-\frac{c^{2}}{\alpha}, \alpha=\frac{2 c}{a+\varepsilon+c}$. However, after offering $\alpha=\frac{2 c}{a+\varepsilon+c}$ for sale, the entrepreneur will soon find out that $M=a c-\frac{c^{2}}{\alpha}=\frac{c(a-\varepsilon-c)}{2}$. Then the firm is not able to produce an optimal quantity from the entrepreneur's point of view and we have $q=\frac{M}{c}=\frac{a-c-\varepsilon}{2}$ and $p=a-\frac{a-c-\varepsilon}{2}=\frac{a+c+\varepsilon}{2}$. The firm's expected profit equals

$$
\left(1-\frac{2 c}{a+\varepsilon+c}\right) \frac{a-c-\varepsilon}{2} \frac{a+c+\varepsilon}{2}=\frac{(a-c)^{2}-\varepsilon^{2}}{4}
$$

Proof of Proposition 3. Consider pooling with equity-based crowdfunding, which is supported by off-equilibrium market beliefs that the firm is $l$ if the market participants observe reward-based crowdfunding. First of all, let us verify non-deviation for each type to reward-based crowdfunding. After shares are sold, the firm chooses $q$ to maximize the entrepreneur's expected profit.

$$
(1-\alpha)\left(p\left(a_{j}-p\right)+M-c q\right)=(1-\alpha)\left(\left(a_{j}-q\right) q+M-c q\right), j=l, h
$$

subject to

$$
M \geq c q
$$

Two cases are possible. 1.

$$
M \geq \frac{c\left(a_{h}-c\right)}{2}
$$

In this case both types of the firm will be able to produce an optimal quantity of goods/services, i.e. it can select the $q$ that is the absolute maximum for (60) as the constraint (62) is not binding. This optimal quantity equals $q=\frac{a_{j}-c}{2}$, $j=l, h$. The cost of production is $c q_{j}=c\left(a_{j}-\frac{a_{j}+c}{2}\right)=\frac{c\left(a_{j}-c\right)}{2} \leq M$ so the constraint (61) holds. Also $p=\frac{a_{j}+c}{2}$.

The entrepreneur's expected profit equals

$$
(1-\alpha)\left(\frac{\left(a_{j}-c\right)^{2}}{4}+M\right)
$$


The funders' expected earnings should cover their investment cost or:

$$
\alpha\left(x\left(\frac{\left(a_{h}-c\right)^{2}}{4}+M\right)+(1-x)\left(\frac{\left(a_{l}-c\right)^{2}}{4}+M\right)\right)=M
$$

This condition means that the market believes that the firm is $h$ with probability $x$. (64) implies:

$$
\begin{gathered}
\alpha=\frac{4 M}{x\left(a_{h}-c\right)^{2}+(1-x)\left(a_{l}-c\right)^{2}+4 M} \\
M=\frac{\alpha\left(x\left(a_{h}-c\right)^{2}+(1-x)\left(a_{l}-c\right)^{2}\right)}{4-4 \alpha}
\end{gathered}
$$

Substituting this into (62), we find that:

$$
\frac{\alpha\left(x\left(a_{h}-c\right)^{2}+(1-x)\left(a_{l}-c\right)^{2}\right)}{4-4 \alpha} \geq \frac{c\left(a_{h}-c\right)}{2}
$$

or

$$
\alpha \geq \frac{2 c\left(a_{h}-c\right)}{x\left(a_{h}-c\right)^{2}+(1-x)\left(a_{l}-c\right)^{2}+2 c\left(a_{h}-c\right)}
$$

If $l$ deviates to reward-based crowdfunding, its payoff equals $\frac{\left(a_{l}-c\right)^{2}}{4}$ which is smaller than its equilibrium payoff. Indeed if we substitute (66) into (63) we have that l's equilibrium payoff equals $(1-\alpha)\left(\frac{\left(a_{l}-c\right)^{2}}{4}+\frac{\alpha\left(x\left(a_{h}-c\right)^{2}+(1-x)\left(a_{l}-c\right)^{2}\right)}{4-4 \alpha}\right)$. It equals $\frac{\left(a_{l}-c\right)^{2}}{4}$ if $x=0$ and it is larger if $x>0$. So $l$ does not deviate. Now consider the potential deviation of type $h$. if $h$ deviates its payoff also equals $\frac{\left(a_{l}-c\right)^{2}}{4}$. This is smaller than its equilibrium payoff since its equilibrium payoff is higher than that of type $l$ and the latter is greater than $\frac{\left(a_{l}-c\right)^{2}}{4}$ as was shown previously. Let us now verify that off-equilibrium beliefs survive the intuitive criterion of Cho and Kreps (1987). To show this, let us calculate the maximal payoff of type $h$ in the case that it plays equity-based crowdfunding. Its payoff is evidently maximized if the market's beliefs place the probability 1 on type $l$ observing equity. If off-equilibrium beliefs survive the intuitive criterion, this expression must be not less than the payoff of $h$ in equilibrium. ${ }^{22}$ It follows from our analysis of the separating equilubrium above that the payoff of $h$ will be higher than its equilibtum payoff if the market places the probbaility of 1 on type $l$.Off-equilibrium beliefs survive the intuitive criterion of Cho and Kreps (1987). The proof is omitted for brevity.

2. $M<\frac{c\left(a_{h}-c\right)}{2}$. In this case only type $l$ will be able to produce an optimal quantity of goods/services, or both types will not be able to produce an optimal quantity of goods/services. The payoff of the entrepreneur is smaller than in the first case so we omit calculations for brevity.

Now consider a pooling equilibrium where both types select reward-based crowdfunding, which is supported by off-equilibrium market beliefs that the firm

${ }^{22}$ Otherwise the market should place the probability 0 that $h$ deviates to equity. 
is $l$ if the market participants observe equity-based crowdfunding. The firm's payoff in equilibrium is

$$
\Pi_{j}=\frac{\left(a_{m}-c\right)^{2}}{4}
$$

where $a_{m}=x a_{h}+(1-x) a_{l} .{ }^{23}$

Now let us analyze the mispricing. Consider pooling with equity-based crowdfunding. $h$ 's profit $\Pi_{h}$ equals $(1-\alpha)\left(\frac{\left(a_{h}-c\right)^{2}}{4}+\frac{\alpha\left(x\left(a_{h}-c\right)^{2}+(1-x)\left(a_{l}-c\right)^{2}\right)}{4-4 \alpha}\right)$. This is greater than $(1-\alpha)\left(\frac{\left(a_{m}-c\right)^{2}}{4}+\frac{\alpha\left(x\left(a_{h}-c\right)^{2}+(1-x)\left(a_{l}-c\right)^{2}\right)}{4-4 \alpha}\right)=\frac{\left(a_{m}-c\right)^{2}}{4}+$ $\frac{\alpha\left(x\left(a_{h}-c\right)^{2}+(1-x)\left(a_{l}-c\right)^{2}-\left(a_{m}-c\right)^{2}\right)}{4}$. This is in turn greater than $\frac{\left(a_{m}-c\right)^{2}}{4}$. Indeed, $x\left(a_{h}-c\right)^{2}+(1-x)\left(a_{l}-c\right)^{2}-\left(a_{m}-c\right)^{2}=x(1-x)\left(a_{h}-a_{l}\right)^{2} \geq 0$.

Proof of Proposition 4. First consider the case where the entrepreneur of the high-quality firm is overconfident. Consider a situation where $l$ selects rewardbased crowdfunding and $h$ selects equity-based crowdfunding. We have (all calculations are based on the symmetric information case for each type described in Section 2):

$$
\begin{gathered}
\Pi_{l}=\frac{\left(a_{l}-c\right)^{2}}{4} \\
\Pi_{h}=\frac{\left(a_{h}-c\right)^{2}-\varepsilon^{2}}{4}
\end{gathered}
$$

where $\Pi_{j}$ is the equilibrium profit of type $j$. The entrepreneur of firm $h$, however, thinks that

$$
\Pi_{l}=\frac{\left(a_{h}+\varepsilon-c\right)^{2}}{4}
$$

$h$ does not deviate to reward-based crowdfunding since it yields a smaller profit from the entrepreneur's point of view: $\frac{\left(a_{l}-c\right)^{2}}{4}$. Consider the potential deviation of $l$. First consider the case when the entrepreneur learns from the sale of shares. Suppose $\alpha>\frac{2 c}{a_{h}-\varepsilon+c}$. Then as follows from the Section 2 analysis of this case

$$
M=\frac{\alpha\left(a_{h}-c\right)^{2}}{4(1-\alpha)}
$$

The entrepreneur of type $l$ will then select

$$
q=\frac{a_{l}-c}{2}
$$

after selling shares and his payoff is $(1-\alpha)\left(\frac{\left(a_{l}-c\right)^{2}}{4}+M\right)$. Taking into account (70) and (71) it equals $\frac{\left(a_{l}-c\right)^{2}}{4}+\frac{\alpha}{4}\left(\left(a_{h}-c\right)^{2}-\left(a_{l}-c\right)^{2}\right) \geq \frac{\left(a_{l}-c\right)^{2}}{4}$ so $l$ will mimick $h$ and this equilibrium does not exist.

Now consider the case when the entrepreneur does not learn from the sales of shares. Suppose the entrepreneur selects $\alpha>\frac{2 c}{a_{h}-\varepsilon+c}$. In this case $M$ is

\footnotetext{
${ }^{23}$ Note that the funders' pre-orders are based on the belief that the quality of the product is average since in a pooling equilibrium all firms use the same strategy.
} 
determined according to (23) and it equals $\frac{\alpha\left(\left(a_{h}-c\right)^{2}-\varepsilon^{2}\right)}{4(1-\alpha)}$. The entrepreneur will select $q=\frac{a_{l}-c}{2}$ and the firm's expected earnings are:

$$
\begin{aligned}
(1-\alpha)((p-c) q+M) & =(1-\alpha)\left(\left(\frac{a_{l}+c}{2}-c\right)\left(a_{l}-\frac{a_{l}+c}{2}\right)+\right. \\
\left.+\frac{\alpha\left(\left(a_{h}-c\right)^{2}-\varepsilon^{2}\right)}{4(1-\alpha)}\right) & =(1-\alpha)\left(\frac{\left(a_{l}-c\right)^{2}}{4}+\frac{\alpha\left(\left(a_{h}-c\right)^{2}-\varepsilon^{2}\right)}{4(1-\alpha)}\right)
\end{aligned}
$$

It equals $\frac{\left(a_{l}-c\right)^{2}}{4}+\frac{\alpha}{4}\left(\left(a_{h}-c\right)^{2}-\varepsilon^{2}-\left(a_{l}-c\right)^{2}\right)$.

This is less than $\frac{\left(a_{l}-c\right)^{2}}{4}$ if $\varepsilon>\sqrt{\left(a_{h}-c\right)^{2}-\left(a_{l}-c\right)^{2}}$.

Now consider a situation where $h$ selects reward-based crowdfunding and $l$ selects equity-based crowdfunding. We have:

$$
\begin{gathered}
\Pi_{l}=\frac{\left(a_{l}-c\right)^{2}}{4} \\
\Pi_{h}=\frac{\left(a_{h}-c\right)^{2}-\varepsilon^{2}}{4}
\end{gathered}
$$

where $\Pi_{j}$ is the equilibrium profit of type $j$. The entrepreneur of firm $h$, however, thinks that

$$
\Pi_{h}=\frac{\left(a_{h}+\varepsilon-c\right)^{2}}{4}
$$

$h$ does not deviate to equity-based crowdfunding since he thinks that the price of shares is too small. Suppose that $l$ mimics $h$ and chooses reward-based crowdfunding instead. The price offered is $\frac{a_{h}+\varepsilon+c}{2}$. His payoff is:

$$
\frac{\left(a_{h}-c\right)^{2}-\varepsilon^{2}}{4}
$$

This is less than $\frac{\left(a_{l}-c\right)^{2}}{4}$ if $\varepsilon>\sqrt{\left(a_{h}-c\right)^{2}-\left(a_{l}-c\right)^{2}}$.

Now consider the case where the entrepreneur of the low-quality firm is overconfident.

Consider a situation where $l$ selects reward-based crowdfunding and $h$ selects equity-based crowdfunding. We have:

$$
\begin{gathered}
\Pi_{h}=\frac{\left(a_{h}-c\right)^{2}}{4} \\
\Pi_{l}=\frac{\left(a_{l}-c\right)^{2}-\varepsilon^{2}}{4}
\end{gathered}
$$

where $\Pi_{j}$ is the equilibrium profit of type $j$. The entrepreneur of firm $l$, however, thinks that

$$
\Pi_{l}=\frac{\left(a_{l}+\varepsilon-c\right)^{2}}{4}
$$

$h$ does not deviate to reward-based crowdfunding since it gives the smaller amount of profit: $\frac{\left(a_{l}-c\right)^{2}-\varepsilon^{2}}{4}$. Consider the potential deviation of $l$. We have (as follows from Lemma 1):

$$
\alpha_{h}=\frac{2 c}{a_{h}+c}
$$




$$
M_{h}=\frac{c\left(a_{h}-c\right)}{2}
$$

Suppose that $l$ mimics $h$ and chooses equity-based crowdfunding instead. First consider the case when the entrepreneur learns from selling shares. The entrepreneur will then select

$$
q=\frac{a_{l}-c}{2}
$$

after selling shares and his payoff is $(1-\alpha)\left(\frac{\left(a_{l}-c\right)^{2}}{4}+M\right)$. Taking into account (76), (77) and (78) it equals $\frac{\left(a_{l}-c\right)^{2}}{4}+\frac{c}{2\left(a_{h}+c\right)}\left(\left(a_{h}-c\right)^{2}-\left(a_{l}-c\right)^{2}\right)$. This is greater than (75) so $l$ will mimick $h$ and this equilibrium does not exist.

Now consider the case when the entrepreneur does not learn from the sale of shares. The entrepreneur will select $q=\frac{a_{l}+\varepsilon-c}{2}$ and the firm's expected earnings are:

$$
\begin{aligned}
(1-\alpha)((p-c) q+M) & =(1-\alpha)\left(\left(\frac{a_{l}+c}{2}-c\right)\left(a_{l}-\frac{a_{l}+c}{2}\right)+\right. \\
\left.+\frac{\alpha\left(\left(a_{h}-c\right)^{2}-\varepsilon^{2}\right)}{4(1-\alpha)}\right) & =(1-\alpha)\left(\frac{\left(a_{l}-c\right)^{2}}{4}+\frac{\alpha\left(\left(a_{h}-c\right)^{2}-\varepsilon^{2}\right)}{4(1-\alpha)}\right)
\end{aligned}
$$

His payoff is then equal to $\frac{\left(a_{l}-c\right)^{2}}{4}+\frac{\alpha}{4}\left(\left(a_{h}-c\right)^{2}-\varepsilon^{2}-\left(a_{l}-c\right)^{2}\right)$.

This is less than $\frac{\left(a_{l}-c\right)^{2}}{4}$ if $\varepsilon>\sqrt{\left(a_{h}-c\right)^{2}-\left(a_{l}-c\right)^{2}}$.

Consider a situation where $h$ selects reward-based crowdfunding and $l$ selects equity-based crowdfunding. We have:

$$
\begin{gathered}
\Pi_{l}=\frac{\left(a_{l}-c\right)^{2}-\varepsilon^{2}}{4} \\
\Pi_{h}=\frac{\left(a_{h}-c\right)^{2}}{4}
\end{gathered}
$$

where $\Pi_{j}$ is the equilibrium profit of type $j$. The entrepreneur of firm $l$, however, thinks that

$$
\Pi_{l}=\frac{\left(a_{l}+\varepsilon-c\right)^{2}}{4}
$$

$h$ does not deviate to equity-based crowdfunding since the price of shares is too small. Suppose that $l$ mimics $h$ and chooses reward-based crowdfunding instead. The price offered is $\frac{a_{h}+\varepsilon+c}{2}$. His payoff is:

$$
\frac{\left(a_{h}-c\right)^{2}}{4}
$$

This is less than $\frac{\left(a_{l}-c\right)^{2}-\varepsilon^{2}}{4}$ if $\varepsilon>\sqrt{\left(a_{h}-c\right)^{2}-\left(a_{l}-c\right)^{2}}$.

\section{References}

Arkrot W, Unger A, and Åhlström E (2017) Crowdfunding from a Marketing Perspective. Thesis http://www.diva-portal.org/smash/get/diva2:1106397/FULLTEXT01.pdf 
Akerloff G (1970) The Market for Lemons: Quality Incertainty and the Market Mechanism. Quarterly Review of Economics 74: 488-500.

Ahlers G, Cumming D, Guenther C, and Schweizer D (2015) Signaling in Equity Crowdfunding. Entrepreneurship Theory and Practice 39(4): 955-980.

Astebro T, Herz H, Nanda R, and Weber R (2014) Seeking the Roots of Entrepreneurship: Insights from Behavioral Economics. Journal of Economic Persepectives 28(3): 49-70.

Belleflamme P, Lambert T, and Schwienbacher A (2014) Crowdfunding: Tapping the Right Crowd. Journal of Business Venturing: entrepreneurship, entrepreneurial finance, innovation and regional development 29(5): 585-609.

Brehmer B (1980) In one word: Not from experience. Acta Psychologica 45(1-3): 223-241.

Cain D, Moore D, and Haran U (2015) Making sense of overconfidence in market entry. Strategic Management Journal 36(1): 1-18.

Chen J, Croson D, Elfenbein D and Hart P (2018) The Impact of Learning and Overconfidence on Entrepreneurial Entry and Exit. Forthcoming, Organization Science. Available at SSRN: https://ssrn.com/abstract $=3140528$ or http://dx.doi.org/10.2139/ssrn.3140528

Cho I-K and Kreps D (1987) Signaling Games and Stable Equilibria. The Quarterly Journal of Economics 102(2): 179-221.

Choe H, Masulis R and Nanda V (1993) Common Stock Offerings Across the Business Cycle. Journal of Empirical Finance 1: 3-31.

Demichelis S and Tarola O (2006) Capacity expansion and dynamic monopoly pricing. Research in Economics 60(4): 169-178.

Everett C and Fairchild R (2015) A Theory of Entrepreneurial Overconfidence, Effort, and Firm Outcomes. Journal of Entrepreneurial Finance 17(1): $1-27$.

Fairchild R (2005) The effect of managerial overconfidence, asymmetric information, and moral hazard on capital structure decisions. ICFAI Journal of Behavioral Finance 2(4).

Fairchild R, Liu W and Yao Y (2017) An Entrepreneur's Choice of CrowdFunding or Venture Capital Financing: The Effect of Entrepreneurial Overconfidence and CF-Investors' Passion. working paper. Available at SSRN: https://ssrn.com/abstract $=2926980$ or http://dx.doi.org/10.2139/ssrn.2926980

Fudenberg D and Tirole J (1991). Game Theory. MIT Press

Gabison G (2015) Understanding Crowdfunding and its Regulations. How can Crowdfunding help ICT Innovation? JRC Science and Policy Report. $10.2791 / 562757$

Giudici G, Nava R, Rossi Lamastra C and C Verecondo (2012) Crowdfunding: The New Frontier for Financing Entrepreneurship? working paper SSRN: https://ssrn.com/abstract $=2157429$.

Hatfield I (2017) Increasing and diversifying finance for high-growth SMEs in the UK's regions. Report.

Hayward M, Shepherd D and Griffin D (2006) A Hubris Theory of Entrepreneurship. Management Science 52(2): 160-172. 
Hildebrand T, Puri M and Rocholl J (2014) Adverse Incentives in Crowdfunding. working paper. Available at SSRN: http://ssrn.com/abstract=1615483. $10.2139 /$ ssrn. 1615483

Hornuf L and Neuenkirch M (2017) Pricing shares in equity crowdfunding. Small Business Economics 48(4): 795-811.

Hu M, Li X and Shi M (2014) Product and Pricing Decisions in Crowdfunding. Rotman School of Management Working Paper No. 2405552. Available at SSRN: http://ssrn.com/abstract=2405552 or http://dx.doi.org/10.2139/ssrn.2405552. $10.2139 /$ ssrn.2405552

Ji X and Miglo A (2018) Capital Structure Choice Under Asymmetric Information and Overconfident Managers. working paper

Kuppuswamy V and Bayus B (2015) A Review of Crowdfunding Research and Findings. Handbook of New Product Development Research, Forthcoming. Available at SSRN: https://ssrn.com/abstract=2685739 or http://dx.doi.org/10.2139/ssrn.2685739. http://dx.doi.org/10.2139/ssrn.2685739

Leland H and Pyle D (1977) Informational Asymmetries, Financial Structure, and Financial Intermediation. Journal of Finance 32(2): 371-87.

Lin T-C and Pursiainen V (2018) Gender Differences in Crowdfunding - Entrepreneur Overconfidence and Campaign Outcomes. working paper. Available at SSRN: https://ssrn.com/abstract=3045050 or http://dx.doi.org/10.2139/ssrn.3045050

Malmendier U, Tate G and Yanv J (2011) Overconfidence and Early-Life Experiences: The Effect of Managerial Traits on Corporate Financial Policies. Journal of Finance 66(5): 1687-1733.

March J, Sproull L and Tamuz M (1991) Learning from Samples of One or Fewer.· Journal Organization Science 2(1): 1-13.

March J and Olsen J (1976) Ambiguity and Choice in Organizations Paperback. Universitetsforlaget.

Miglo A (2018) Crowdfunding in a Duopoly Under Asymmetric Information. working paper. Available at SSRN: https://ssrn.com/abstract=3193864

Miglo A and Miglo V (2018) Market Imperfections and Crowdfunding. Small Business Economics, Forthcoming.

Modigliani F and Miller M (1958) The Cost of Capital, Corporation Finance and the Theory of Investment. American Economic Review 48(3): 261-297.

Mollick M (2014) The dynamics of crowdfunding: An exploratory study. Journal of Business Venturing 29: 1-16.

Moritz A and Block J (2014) Crowdfunding: A Literature Review and Research Directions. working paper. Available at SSRN: http://ssrn.com/abstract $=2554444$ or http://dx.doi.org/10.2139/ssrn.2554444. 10.2139/ssrn.2554444

Myers S and Majluf N (1984) Corporate Financing Decisions When Firms Have Information Investors Do Not Have. Journal of Financial Economics 13: 187-221.

Nachman D and Noe T (1994) Optimal Design of Securites under Asymmectric Information. Review of Financial Studies 7: 1-44.

Puiu T (2016) Confronting overconfidence with actual performance promotes learning. ZME science website. https://www.zmescience.com/medicine/mindand-brain/overconfidence-and-learning/ 
Titman S and Wessels R (1988) The Determinants of Capital Structure Choice. Journal of Finance 43: 1-19.

Zhang N, Datta S and Kannan, K. N. (2015) An Analysis of Incentive Structures in Collaborative Economy: An Application to Crowdfunding Platform. SSRN Working Paper. http://dx.doi.org/10.2139/ssrn.2518662 